\title{
Pemodelan dan Simulasi Proses Adsorpsi Gas Pengotor oleh Molecular Sieve pada Pendingin Rde dengan Software Chemcad
}

\author{
Atiqah M. Hilda ${ }^{1}$, Sriyono ${ }^{2 *}$, Mia Kamayani ${ }^{1}$ \\ ${ }^{1}$ Fakultas Teknik, Universitas Muhammadiyah Prof. Dr. Hamka, \\ Jalan Tanah Merdeka No. 6B, Kampung Rambutan Jakarta Timur 13830 \\ ${ }^{2}$ Pusat Teknologi dan Keselamatan Reaktor Nuklir (PTKRN), \\ BATAN, Gedung 80, Kawasan Puspiptek, Serpong, Tangerang Selatan, BANTEN. \\ Telp.: 62-21-7560912, Fax.: 62-21-7560913, Kode Pos : 15310, *E-mail: sriyono@ batan.go.id
}

\begin{abstract}
Abstrak - RDE10 adalah reaktor yang didesain menggunakan gas helium sebagai pendingin. Sistem pendingin ini harus selalu dijaga kemurniannya dari berbagai gas pengotor dengan menggunakan Sistem Pemurnian Helium (SPH). Gas pengotor terjadi akibat adanya water atau air ingress yang masuk ke sistem pendingin dan bereaksi dengan grafit $(C)$. Gas-gas pengotor yang terjadi adalah $\mathrm{CH}_{4}, \mathrm{CO}, \mathrm{CO}_{2}, \mathrm{H}_{2} \mathrm{O}, \mathrm{H}_{2}, \mathrm{O}_{2}$, dan $\mathrm{N}_{2}$. Adanya gas pengotor di dalam pendingin memicu terjadinya oksidasi ataupun karburisasi-dekarburisasi oleh karenanya konsentrasinya dalam pendingin harus dijaga serendah mungkin. Salah satu tahapan proses dalam SPH adalah penyerapan pengotor oleh Molecular Sieve terutama untuk gas $\mathrm{CO}_{2}$ dan $\mathrm{H}_{2} \mathrm{O}$. Makalah ini membahas pengaruh tekanan terhadap kemampuan daya serap Molecular Sieve yang dikenal dengan pressure swing adsorption (PSA). Analisis bertujuan untuk mengetahui tekanan paling efektif yang akan dioperasikan pada kolom Molecular Sieve. Molecular Sieve dimodelkan dengan software ChemCAD dalam bentuk 2 unit operasi adsorpsi, satu unit untuk proses penyerapan (sorpsi), dan yang lainnya standby untuk proses regenerasi (desorpsi). Metode adsorpsi yang digunakan dalam analisis adalah metode Langmuir. Model yang telah dibuat disimulasikan dengan memberikan masukan: laju alir total 1,2 $\mathrm{kg} / \mathrm{sec}$, temperatur $30^{\circ} \mathrm{C}$, porositas 0,7 , tinggi bed diasumsikan $2 \mathrm{~m}$, diameter pori-pori $5 \mathrm{~A}$, dan jumlah pengotor $\mathrm{CO}_{2}$ dan $\mathrm{H}_{2} \mathrm{O}$ masing-masing $1 \mathrm{~g} / \mathrm{s}$. Tekanan divareasikan dari 5 sampai dengan 50 bar, perubahan daya serap Molecular Sieve dianalisis. Hasil analisis menunjukkan bahwa dengan adanya variasi kenaikan tekanan dari 5 sampai 50 bar, menunjukkan adanya kenaikan daya serap Molecular Sieve terhadap $\mathrm{CO}_{2}$ sebesar 15,90\% dan $\mathrm{H}_{2} \mathrm{O}$ sebesar 15,80\%. Pada desain SPH, aliran input ke Molecular Sieve harus dikompresikan sampai dengan 50 bar untuk mendapatkan daya serap tinggi terhadap proses penyerapan pengotor $\mathrm{CO}_{2}$ dan $\mathrm{H}_{2} \mathrm{O}$.
\end{abstract}

Kata kunci : pressure swing adsorption, Molecular Sieve, gas pengotor, RDE10

\begin{abstract}
The purity of RDE10 helium coolant should be maintained from various impurities gas due to water/air ingress that reacts with the reflector graphite $(\mathrm{C})$. These impurities are $\mathrm{CH}_{4}, \mathrm{CO}, \mathrm{CO}_{2}$, $\mathrm{H}_{2} \mathrm{O}, \mathrm{H}_{2}, \mathrm{O}_{2}$, and $\mathrm{N}_{2}$ which can initiate oxidation corrosion or carburization-decarburization so the concentration should be maintain to be a minimum. The helium coolant is purified by Helium Purification System (HPS). One of the stages in HPS is adsorption by Molecular Sieve mainly for $\mathrm{CO}_{2}$ and $\mathrm{H}_{2} \mathrm{O}$ molecules. This paper discusses the influence of pressure, known as pressure swing adsorption (PSA) on the adsorption ability of the Molecular Sieve aims to determine the most effective pressure that will be operated on Molecular Sieve column. Molecular Sieve is modeled with CHEMCAD computer code in two columns, one column for the adsorption process, and the other for the regeneration (desorption). Adsorption methods used in the analysis is the Langmuir method. Models that have been developed simulated by providing input: total flow rate of $10.5 \mathrm{~kg} / \mathrm{hour}, 30^{\circ} \mathrm{C}$, porosity 0.7, bed height $2 \mathrm{~m}$, pore diameter $5 \mathrm{~A}$, and the amount of $\mathrm{O}_{2}$ and $\mathrm{N}_{2}$ impurities respective each $1 \mathrm{~g} / \mathrm{s}$. The pressure varies between 5 to 50 bars, and the Molecular Sieve adsorption capability is analyzed. Simulation results show that with the increase in pressure of 5 to 50 bar, indicating an increase in Molecular Sieve absorption capacity to $\mathrm{CO}_{2}$ is $15.90 \%$ and to $\mathrm{H}_{2} \mathrm{O}$ is $15.80 \%$. In the $\mathrm{SPH}$ design, the input stream to the Molecular Sieve must be compressed until 50 bar to obtain high absorption capability of the $\mathrm{CO}_{2}$ and $\mathrm{H}_{2} \mathrm{O}$.
\end{abstract}

Keywords: pressure swing adsorption, Molecular Sieve, gas impurities, RDE10 


\section{Pendahuluan}

Reaktor Daya Eksperimental $10 \mathrm{MW}_{\text {th }}$ (RDE10) adalah reaktor berpendingin gas temperatur tinggi yang dikembangkan dan didesain oleh PTKRN-BATAN. Reaktor ini dibangun untuk penelitian dan demonstrasi pembangkitan daya listrik. RDE10 berdaya $10 \mathrm{MW}$ thermal, siklus konversi energi tak langsung dan menggunakan gas helium sebagai pendingin primer. Gas helium mempunyai banyak keunggulan, seperti bersifart inert (tidak mudah bereaksi dengan gas lain), memiliki kapasitas panas (heat capacity) yang tinggi, dan tampang lintang (cross section) netron rendah ${ }^{[1]}$. Selama reaktor RDE10 beroperasi, sistem pendingin helium dimungkinkan terkontaminasi dari berbagai pengotor ${ }^{[2]}$. Pengotor yang terjadi dalam aliran pendingin dibedakan dalam 2 kategori yaitu pengotor berbentuk partikulat padat (pada umumnya berbentuk debu karbon lepasan dari bahan bakar bola, dan radionuklida produk fisi), dan pengotor berbentuk gas ${ }^{[2,3]}$. Pengotor berbentuk gas yang terbawa dalam aliran pendingin helium dapat terjadi dari berbagai sumber. Berdasarkan pengalaman pengoperasian HTGR (High Temperature Gas Cooled Reactor) di dunia antara lain : Arbeitsgemeinschaft Versuchsreaktor (AVR) Jerman; Fort Saint Vrain Amerika Serikat, dan HTR-10 China, gas-gas pengotor tersebut dapat berasal dari : proses degassing reflektor grafit (menghasilkan pengotor $\mathrm{CO}, \mathrm{CO}_{2}, \mathrm{H}_{2} \mathrm{O}, \mathrm{H}_{2}$ dan $\mathrm{N}_{2}$ ); proses loading dan unloading bahan bakar (menghasilkan pengotor $\mathrm{CO}, \mathrm{CO}_{2}, \mathrm{H}_{2} \mathrm{O}, \mathrm{H}_{2}$ dan $\mathrm{CH}_{4}$ ); proses welding dan penyambungan sistem pemipaan pada saat perawatan (menghasilkan gas pengotor $\mathrm{O}_{2}, \mathrm{~N}_{2}$ ); proses degassing dari dalam struktur logam (menghasilkan pengotor $\mathrm{O}_{2}, \mathrm{H}_{2} \mathrm{O}, \mathrm{H}_{2}$ dan $\mathrm{N}_{2}$ ); proses degassing insulator thermal (menghasilkan $\mathrm{O}_{2}, \mathrm{CO}_{2}, \mathrm{H}_{2} \mathrm{O}$, dan $\mathrm{N}_{2}$ ). Gas-gas pengotor tersebut akan memicu terjadinya proses korosi oksidasi dan karburisasi-dekarburisasi ${ }^{[3]}$ sehingga harus dibersihkan dalam aliran pendingin.

Untuk menjamin bahwa helium bersih dari pengotor, pada sistem pendingin RDE10, didesain sebuah

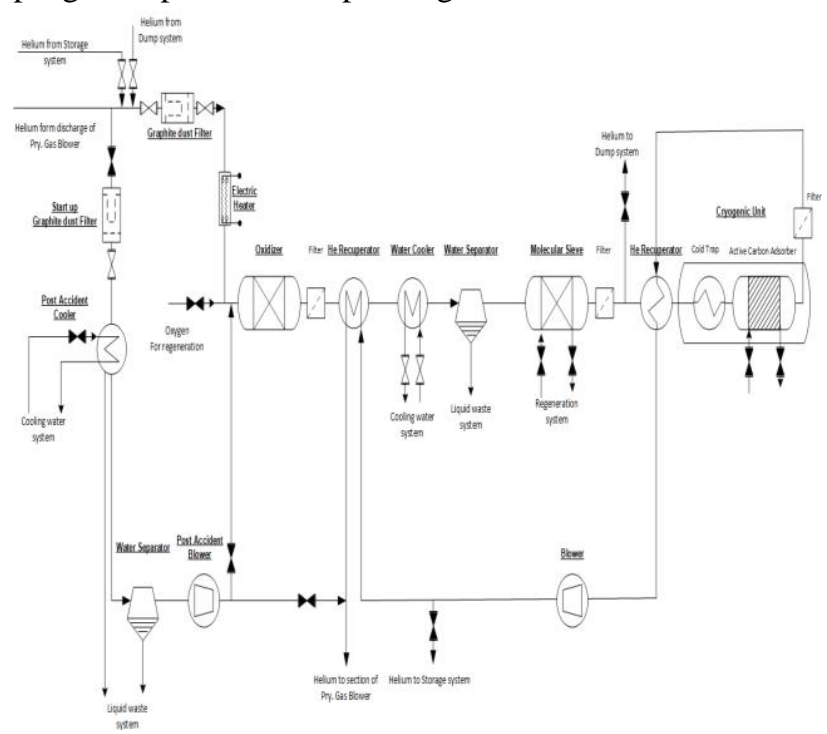

Sistem Pemurnian Helium (SPH). SPH dirancang dalam satu perangkat (train) yang berfungsi ganda yaitu digunakan pada operasi normal dan kondisi kecelakaan (accident). Dalam SPH terdapat beberapa tahap proses pembersihan pengotor yaitu penyaringan debu karbon dengan filter HEPA (High Efficiency Particulate Air), proses oksidasi dengan oksidator $\mathrm{CuO}$, proses penyerapan pengotor dengan Molecular Sieve, dan proses penyerapan dengan kriogenik karbon aktif ${ }^{[4]}$. Filter HEPA berfungsi menyaring debu karbon dan radionuklida produk fisi yang terbawa dalam aliran. Kolom oksidasi $\mathrm{CuO}$ untuk mengoksidasi gas $\mathrm{CO}$ dan $\mathrm{H}_{2}$ menjadi $\mathrm{CO}_{2}$ dan $\mathrm{H}_{2} \mathrm{O}$ sehingga mampu diserap pada tahapan adsorpsi Molecular Sieve. Kolom Molecular Sieve berguna untuk menyerap gas $\mathrm{NO}_{\mathrm{x}}, \mathrm{CO}_{2}, \mathrm{H}_{2} \mathrm{O}, \mathrm{CH}_{4}$, sedangkan kriogenik karbon aktif digunakan untuk menyerap gas $\mathrm{N}_{2}$ dan $\mathrm{O}_{2}$ yang masih lolos dari Molecular Sieve karena ukurannya sangat kecil.

Makalah ini membahas pemodelan dan simulasi proses penyerapan gas pengotor pada Molecular Sieve dengan metode pressure swing adsorption (PSA). Molecular Sieve dimodelkan dengan paket program ChemCAD dalam 2 kolom/bed, kolom pertama sebagai proses sorpsi pada operasi normal dan kolom kedua sebagai kolom standby. Kedua kolom beroperasi secara bergantian, ketika satu kolom beroperasi maka satu kolom yang lain diregenerasi (desorpsi). Desorpsi dilakukan untuk meregenerasi Molecular Sieve apabila telah mengalami kejenuhan dengan cara menurunkan tekanan sistem menjadi tekanan atmosfer. Metode penyerapan (sorpsi) pada Molecular Sieve yang digunakan adalan metode Langmuir. Tujuan pemodelan dan simulasi pada makalah ini adalah untuk mengetahui efektifitas penyerapan pengotor $\mathrm{CO}_{2}$ dan $\mathrm{H}_{2} \mathrm{O}$ dalam kolom Molecular Sieve. Sudah banyak penelitian terdahulu yang dilakukan terutama di negaranegara yang membangun dan mengoperasikan reaktor HTGR. Setiap reaktor memiliki karakteristik yang berbeda termasuk daya dan laju alir pendingin primer. Karena keunikan dan perbedaan RDE maka penelitian ini dilakukan. Dengan proses penyerapan pada kolom molecular sieve ini diharapkan gas $\mathrm{CH}_{4}, \mathrm{H}_{2} \mathrm{O}, \mathrm{CO}_{2}$ dan beberapa produk fisi dapat terambil.

\section{Dasar Teori}

\section{Deskripsi Sistem Pemurnian Helium RDE}

RDE10 menggunakan siklus tak langsung langsung (direct cycle), aliran pendingin helium mengambil panas dari teras reaktor kemudian panasnya dapat dimanfaatkan sebagai pendukung proses produksi hidrogen, pembangkit listrik dan desalinasi ${ }^{[5]}$. Aliran ini mempunyai laju sebesar $4,3 \mathrm{~kg} /$ detik, dengan temperatur keluar teras $750^{\circ} \mathrm{C}$ dan tekanan $30 \mathrm{bar}^{[4]}$. Aliran pendingin helium dimurnikan dengan Sistem Pemurnian Helium (SPH), mengambil sebagian $(1 \%)$ aliran pendingin utama. Temperatur aliran adalah sekitar $250{ }^{\circ} \mathrm{C}$ dan tekanan masuk ke SPH 30 bar. Rancangan SPH ditunjukkan pada Gambar $1^{[2,4]}$. Desain konseptual SPH pada RDE10 meliputi proses-proses sebagai berikut

Gambar 1. Desain Konseptual SPH RDE10 ${ }^{[3]}$ 
- Proses Filtrasi Debu Karbon dan Partikel Padatan Lain.

- Filtrasi partikulat padat terutama debu karbon yang terkandung dalam helium pendingin primer dilakukan sebelum masuk ke reaktor $\mathrm{CuO}$, menggunakan filter HEPA khusus (High Efficiency Particulate Air/HEPA) pada kondisi temperatur $250^{\circ} \mathrm{C}$, dan tekanan $3 \mathrm{MPa}^{[7]}$. Debu karbon berukuran

- Kolom (bed) Oksidator CuO.

Karena pengotor gas $\mathrm{H}_{2}$ dan $\mathrm{CO}$ sulit untuk diserap baik oleh penyaring molekuler ataupun karbon aktif maka tahapan selanjutnya adalah mengkonversi gas $\mathrm{H}_{2}$ dan $\mathrm{CO}$ menjadi $\mathrm{H}_{2} \mathrm{O}$ dan $\mathrm{CO}_{2}$ melalui kolom oksidator $\mathrm{CuO}$ (reaktor $\mathrm{CuO}$ ) pada temperatur $250{ }^{\circ} \mathrm{C}$. Dalam proses ini $\mathrm{CH}_{4}$ juga akan mengalami oksidasi menghasilkan $\mathrm{H}_{2} \mathrm{O}$ dan $\mathrm{CO}_{2}$ berdasarkan reaksi sbb :

- $\mathrm{H}_{2}+\mathrm{CuO} \rightarrow \mathrm{H}_{2} \mathrm{O}+\mathrm{Cu}$.

- $\mathrm{CO}+\mathrm{CuO} \rightarrow \mathrm{CO}_{2}+\mathrm{Cu}$.

- $\mathrm{CH}_{4}+4 \mathrm{CuO} \rightarrow 2 \mathrm{H}_{2} \mathrm{O}+\mathrm{CO}_{2}+4 \mathrm{Cu}$.

Dengan demikian maka seluruh spesi yang sulit untuk diserap dapat dihilangkan. Jika oksidator jenuh maka dilakukan regenerasi menggunakan Oksigen pada suhu $250{ }^{\circ} \mathrm{C}$.

- Adsorpsi dengan Molecular Sieve.

Setelah proses koversi gas gas $\mathrm{H}_{2}$ dan $\mathrm{CO}$ menjadi $\mathrm{H}_{2} \mathrm{O}$ dan $\mathrm{CO}_{2}$ dilakukan maka selanjutnya gas helium pendingin primer dilewatkan melalui kolom penyaring molekuler (Molecular Sieve) yang beroperasi pada temperatur kamar $\left(30^{\circ} \mathrm{C}\right)$ dan tekanan tertentu. Pada

1.Adsorpsi : proses penyerapan pada tekanan tinggi.

2.Purging : proses penurunan tekanan dari tekanan adsorpsi sampai $\mathrm{P}$ tertentu.

3.Desorpsi : adsorbat pada adsorben didesorpsi pada tekanan rendah menggunakan gas produk.

4.Represurisasi : proses penaikan tekanan dari tekanan rendah ke tekanan operasi adsorpsi, dengan mengalirkan sebagian flow produk.

kolom ini akan terjadi adsorpsi gas $\mathrm{CO}_{2}, \mathrm{CH}_{4}, \mathrm{H}_{2} \mathrm{O}$ dan beberapa produk fisi berbentuk gas.

- Adsorpsi dengan Karbon Aktif pada Kondisi Kriogenik.

Proses selanjutnya adalah dilakukan adsorpsi pada kondisi kriogenik (temperatur sangat rendah $-180{ }^{\circ} \mathrm{C}$ ) menggunakan karbon aktif untuk menyerap gas oksigen $\left(\mathrm{O}_{2}\right)$, Nitrogen $\left(\mathrm{N}_{2}\right)$, dan seluruh spesi gas sisa yang tidak terserap oleh penyaring molekuler. Kondisi temperatur yang sangat rendah bertujuan untuk meningkatkan kapasitas serapan. Namun dalam proses ini tidak diperbolehkan ada air karena air akan membeku dan menutup kolom sehingga sebelum masuk ke kolom kriogenik karbon aktif harus ditambahkan Komponen Kondensator/Separator Uap air. Regenerasi karbon aktif dilakukan dengan memanaskan karbon aktif jenuh pada temperatur dan tekanan tertentu sehingga pengotor yang terikat terdesorpsi kembali.

Dengan pertimbangan bahwa proses operasi purifikasi tersebut berada pada berbagai kondisi temperatur yang berbeda-beda, maka SPH didesain dengan tambahan berbagai komponen seperti : pemanas (heater), penukar panas, pendingin (cooler), kompressor dan ekonomiser yang diatur konfigurasinya sedemikian sehingga dapat mengoptimalkan biaya operasi sistem ${ }^{[2,4]}$.

\section{Pressure Swing Adsorption (PSA)}

Pressure swing adsorption adalah proses adsorpsi berdasarkan pada kecenderungan gas untuk tertangkap pada

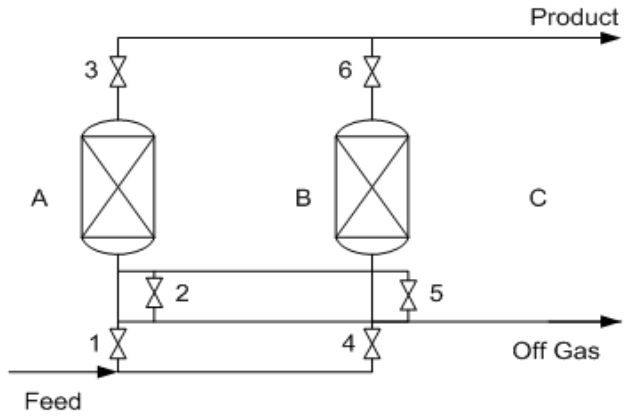

tekanan tinggi dan terdesorpsi pada tekanan yang lebih rendah $^{[6]}$. Proses pressure swing adsorption (PSA) berguna untuk memurnikan produk yang diinginkan hingga tingkat yang sangat kecil bergantung dengan adsorben (bahan penyerap) yang digunakan. Adsorben yang digunakan untuk pressure swing adsorption sangat tergantung dengan jenis dan konsentrasi pengotor yang ingin dibersihkan. Konfigurasi kolom PSA yang digunakan, dapat 2 kolom, 4 kolom, dan bahkan lebih ${ }^{[7]}$. Akan tetapi, konfigurasi 2 kolom yang bekerja secara bergantian adalah konfigurasi yang sangat umum dan paling sederhana untuk digunakan. Diagram alir sederhana kolom PSA ditunjukkan pada Gambar 2. Tahapan proses pada PSA 2 kolom secara bergantian adalah :

Gambar 2. Diagram alir susunan Kolom Pressure Swing Adsorption (PSA) dengan menggunakan 2 kolom

\section{Proses Adsorpsi dengan Molecular Sieve}

Salah satu material yang dapat digunakan sebagai Molecular Sieve adalah Zeolit. Zeolit adalah senyawa zat kimia alumino-silikat berhidrat dengan kation natrium, kalium dan barium ${ }^{[9]}$. Secara umum, Molecular Sieve memiliki sruktur yang unik, di mana atom Silikon dikelilingi oleh 4 atom oksigen sehingga membentuk semacam jaringan dengan pola yang teratur. Di beberapa tempat di jaringan ini, atom Silikon digantikan degan atom Aluminium, yang hanya terkoordinasi dengan 3 atom Oksigen. Atom Aluminium ini hanya memiliki muatan 3+, sedangkan Silikon sendiri memiliki muatan 4+. Keberadaan atom Aluminium ini secara keseluruhan akan menyebabkan 
Molecular Sieve memiliki muatan negatif. Muatan negatif inilah yang menyebabkan Molecular Sieve mampu mengikat kation, dalam hal ini pengotor gas helium.

Tahapan ketiga dari proses pemurnian helium adalah penangkapan gas pengotor dengan menggunakan Molecular Sieve. Molecular Sieve yang umum digunakan adalah Zeolit Tipe 5A. Gas pengotor yang dapat ditangkap dengan Zeolit adalah $\mathrm{NO}_{\mathrm{x}}, \mathrm{CO}_{2}, \mathrm{H}_{2} \mathrm{O}, \mathrm{CH}_{4}$. Spesifikasi Zeolit yang digunakan seperti ditunjukkan pada Tabel 1. ${ }^{[10]}$

Tabel 1. Spesifikasi Zeolit Tipe 5A yang digunakan pada SPH

\begin{tabular}{|l|l|}
\hline \multicolumn{1}{|c|}{ Parameter } & \multicolumn{1}{c|}{ Nilai } \\
\hline Volume pori per gram & $0,3 \mathrm{~cm}^{3}$ \\
\hline Diameter pori & $5 \AA$ \\
\hline Ukuran partikel & $1,6 \mathrm{~mm}$ \\
\hline $\begin{array}{l}\text { Luas permukaan per } \\
\text { gram }\end{array}$ & $700 \mathrm{~s} / \mathrm{d} 800 \mathrm{~m}^{2}$ \\
\hline Porositas internal & 0,7 \\
\hline
\end{tabular}

Pada desain kolom Molecular Sieve ini, biasanya kolom dibuat menjadi 2 macam, kolom pertama untuk kolom adsorpsi (penjeraban), yaitu penyaringan molekul, sedangkan kolom ke dua digunakan untuk regenerasi. Proses ini dilakukan secara bergantian. Proses regenerasi sangat dibutuhkan untuk membersihkan kembali Zeolit dari gas pengotor yang ditangkap sehingga dapat digunakan kembali. Pada proses adsorpsi ini tidak semua gas pengotor dapat diserap, melainkan masih ada kemungkinan gas $\mathrm{N}_{2}$ dan $\mathrm{O}_{2}$ yang terlepas, karena ukuran molekulnya lebih kecil dari 5A. Kedua gas ini akan ditangkap menggunakan Bed Karbon Aktif ${ }^{[11]}$.

\section{Metodologi Penelitian}

Proses adsorpsi dengan Molecular Sieve dimodelkan dengan software ChemCAD ${ }^{[12]}$. Metode yang digunakan adalah metode Langmuir secara isotermis dengan asumsi bahwa adsorpsi hanya terjadi pada lapisan tunggal (monolayer) dengan gas pengotor terserap pada permukaan adsorben. Selain itu proses adsorpsi yang terjadi merupakan proses adsorpsi fisika karena terjadi pada temperatur tetap $\left(30^{\circ} \mathrm{C}\right)$ sehingga persamaan Langmuir lebih cocok digunakan. Konstanta Langmuir a dan b untuk adsorbat gas $\mathrm{CO}_{2}$ dan $\mathrm{H}_{2} \mathrm{O}$ berturut-turut adalah 0,0238; 0,0230 dan 0,013; 0,014 berdasarkan eksperimen yang telah dilakukan oleh Ganga P. Dangi dkk. ${ }^{[10]}$

Tipe Molecular Sieve yang dimodelkan adalah Molecular Sieve 5A. Molecular Sieve tipe 5A dipilih, karena pengotor gas helium terutama $\mathrm{CO}_{2}$ dan $\mathrm{H}_{2} \mathrm{O}$, yang akan diserap berukuran lebih besar dari 5A. Parameter Molecular Sieve 5A yang diinputkan pada model seperti tercantum pada Tabel 1 antara lain : laju alir total $10 \mathrm{~kg} / \mathrm{hour}$, temperatur $30^{\circ} \mathrm{C}$, porositas 0,7 , tinggi bed diasumsikan $2 \mathrm{~m}$, diameter pori-pori $5 \mathrm{~A}$, dan jumlah pengotor $\mathrm{O}_{2}$ dan $\mathrm{N}_{2}$ masing-masing $1 \mathrm{~g} / \mathrm{s}$ atau setara dengan $1000 \mathrm{ppm}$. Tekanan divareasikan dari 5 sampai dengan 50 bar, perubahan daya serap Molecular Sieve dianalisis.

Hasil pemodelan Molecular Sieve dengan ChemCAD ditunjukkan pada Gambar 3. Pada Gambar 3, dimodelkan tahapan pemurnian helium mulai dari Cyclone Separator, filter HEPA, kolom oksidasi $\mathrm{CuO}$ dan adsorpsi Molecular Sieve. Cyclone digunakan untuk memisahkan debu berukuran besar (>10 mikron), sedangkan filter HEPA digunakan untuk menyaring debu karbon berukuran kecil yang masih lolos dari Cyclone sehingga gas helium keluar dari filter HEPA telah bersih dari pengotor debu. Pada kolom $\mathrm{CuO}$, dimodelkan dengan sebuah reaktor kinetik, dengan persamaan yang digunakan adalah persamaan (1), (2) dan (3). Gas pengotor terutama $\mathrm{H}_{2}, \mathrm{CO}$ dan $\mathrm{CH}_{4}$ dioksidasi dengan katalis $\mathrm{CuO}$ sehingga dihasilkan $\mathrm{H}_{2} \mathrm{O}$ dan $\mathrm{CO}_{2}$. Kedua molekul ini mempunyai ukuran yang lebih besar sehingga diharapkan mudah ditangkap oleh Molecular Sieve.

Pada pemodelan Molecular Sieve, unit operasi yang digunakan adalah GA (Gas Adsorption) dibuat dengan 2 unit operasi GA. Masing-masing unit mewakili sebuah Kolom/Bed yang terisi oleh Molecular Sieve. Satu kolom sebagai proses adsorpsi (in operation) dan satu yang lain sebagai cadangan (standby). Kedua kolom beroperasi secara bergantian ketika melakukan proses adsorpsi dan desorpsi (regenerasi). Setelah dioperasikan pada rentang waktu tertentu, maka Molecular Sieve akan mengalami kejenuhan sehingga harus diregenerasi. Analisis neraca massa pada Molecular Sieve dilakukan dengan asumsi: konsentrasi gas pengotor masuk dalam Molecular Sieve adalah keluaran dari kolom oksidator $\mathrm{CuO}$.
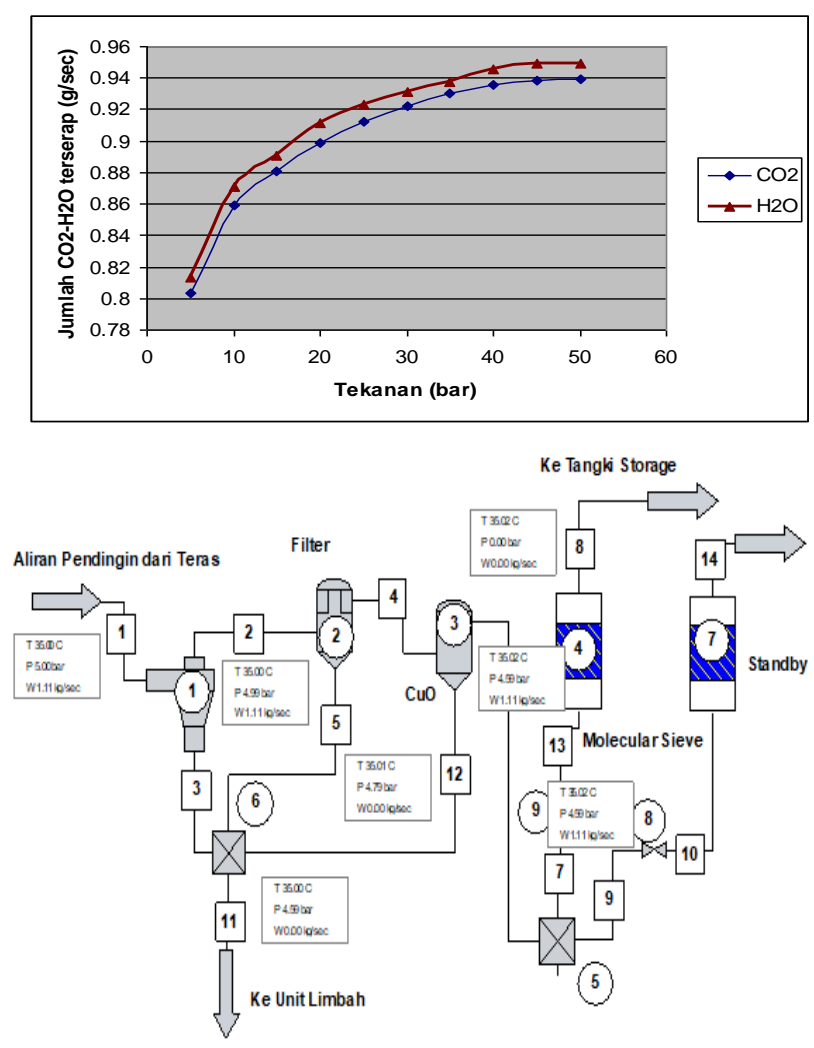

Gambar 3. Pemodelan Unit Operasi Molecular Sieve dengan ChemCAD 


\section{Temuan dan Pembahasan}

Proses pengambilan gas pengotor pada tahap ketiga di SPH RDE10 adalah proses adsorpsi dengan Molecular Sieve. Pada kolom Molecular Sieve, gas pengotor utama yang akan diserap adalah $\mathrm{CO}_{2}$ dan $\mathrm{H}_{2} \mathrm{O}$. Kedua gas ini adalah hasil keluaran pada proses tahap sebelumnya yaitu Kolom Oksidator $\mathrm{CuO}$ yang mengkonversi $\mathrm{CO}$ dan $\mathrm{H}_{2}$ menjadi $\mathrm{CO}_{2}$ dan $\mathrm{H}_{2} \mathrm{O}$ dengan katalis $\mathrm{CuO}$. Proses pengkonversian dilakukan agar ukuran molekul menjadi lebih besar sehingga mudah ditangkap dengan adsorpsi Molecular Sieve.

Pada proses adsorpsi, faktor tekanan sangat menentukan daya serap yang akan terjadi pada Molecular Sieve seperti diungkapkan oleh Perry ${ }^{[9]}$. Pada sisi input SPH tekanan sistem adalah 50 bar dan temperatur $116^{\circ} \mathrm{C}$, tetapi untuk mendapatkan efisiensi proses pada setiap tahapan pada SPH, tekanan dan temperatur ini disesuaikan. Penyesuaian setiap proses dilakukan dalam desain SPH dengan menambahkan komponen tertentu, seperti menggunakan pendinging (Cooler) untuk menurunkan temperatur, pemanas (heater) untuk menaikkan temperatur, Kompressor untuk menaikkan tekanan, dan ataupun Expander untuk menurunkan tekanan.

Aliran keluaran Kolom Oksidator $\mathrm{CuO}$ mempunyai temperatur $30^{\circ} \mathrm{C}$, dan tekanan 5 bar. Dengan metode adsorpsi Langmuir isotermis, maka temperatur tidak perlu mengalami perubahan dan diharapkan selalu tetap. Pada adsorpsi Molecular Sieve, temperatur yang terbaik adalah temperatur kamar sehingga temperatur $30^{\circ} \mathrm{C}$ yang berasal dari keluran kolom $\mathrm{CuO}$ tidak perlu dilakukan perubahan. Pada proses adsorpsi gas, semakin tinggi temperatur akan menurunkan daya serap Molecular Sieve ${ }^{[13]}$. Hal ini dikarenakan pada temperatur tinggi, kinetika gerak molekus gas menjadi lebih dinamis sehingga mempersulit penangkapan gas ke dalam porositas Molecular Sieve. Pada temperatur yang tinggi pula, setelah gas pengotor tertangkap dalam porositas permukaan Molecular Sieve maka gas tersebut akan mudah terlepas kembali.

Pengaruh tekanan terhadap daya serap adsorpsi harus diteliti untuk mendapatkan hasil penyerapan pengotor $\mathrm{CO}_{2}$ dan $\mathrm{H}_{2} \mathrm{O}$ yang optimal. Hasil simulasi dengan software ChemCAD menunjukkan adanya perubahan daya serap terhadap perubahan tekanan yang diberikan ke Kolom Molecular Sieve. Hubungan tekanan dengan jumlah $\mathrm{CO}_{2}$ dan $\mathrm{H}_{2} \mathrm{O}$ yang diserap ditunjukkan pada Gambar 4 .

Gambar 4. Hubungan Tekanan dengan Jumlah $\mathrm{CO}_{2}-\mathrm{H}_{2} \mathrm{O}$ terserap dalam Molecular Sieve

Semakin tinggi tekanan yang diberikan ke sistem maka semakin besar pula jumlah $\mathrm{CO}_{2}$ dan $\mathrm{H}_{2} \mathrm{O}$ yang terserap. Jumlah $\mathrm{H}_{2} \mathrm{O}$ yang terserap lebih banyak dibandingkan dengan jumlah $\mathrm{CO}_{2}$ yang terserap oleh Molecular Sieve. Hal ini diakibatkan bahwa $\mathrm{H}_{2} \mathrm{O}$ adalah molekul polar sedangkan $\mathrm{CO}_{2}$ adalah molekul non polar. Molekul polar lebih mudah tertangkap dalam porositas Molecular Sieve dibandingkan molekul non polar. Polaritas molekul adalah salah satu parameter yang mempengaruhi jumlah konsentrasi yang tertangkap dalam Molecular Sieve selain PSA (pressure swing adsorption). Kecenderungan hasil simulasi sesuai dengan penelitian yang telah dilakukan oleh MYERS dkk. ${ }^{[13,14]}$

Pengaruh tekanan terhadap pengambilan pengotor $\mathrm{CO}_{2}$ dan $\mathrm{H}_{2} \mathrm{O}$ sangat besar. Pada tekanan yang lebih tinggi maka gas-gas pengotor ini akan dipaksa untuk masuk ke dalam pori-pori Molecular Sieve melalui fenomena PSA (Pressure Swing Adsorption) $)^{[7]}$. Ketika tekanan yang diberikan ke Kolom Molecular Sieve semakin bertambah maka jumlah gas pengotor yang tertangkap juga semakin besar. Kenaikan jumlah gas $\mathrm{CO}_{2}$ dan $\mathrm{H}_{2} \mathrm{O}$ yang tertangkap pada berbagai variasi tekanan ditunjukkan pada Tabel 2.

Berdasarkan hasil simulasi ini, maka dalam desain SPH terutama pada tahapan proses penyaringan dengan Molecular Sieve, harus dikondisikan bahwa tekanan masuk ke Kolom Molecular Sieve sebesar 50 bar.

Tabel 2. Prosentasi kenaikan jumlah $\mathrm{H}_{2} \mathrm{O}$ dan $\mathrm{CO}_{2}$ yang terserap pada berbagai perubahan tekanan

\begin{tabular}{|c|c|c|}
\hline $\begin{array}{c}\text { Perubahan } \\
\text { tekanan } \\
\text { (bar) }\end{array}$ & $\begin{array}{c}\text { Kenaikan } \\
\text { jumlah } \mathbf{H}_{\mathbf{2}} \mathbf{O} \\
\text { terserap }(\%)\end{array}$ & $\begin{array}{c}\text { Kenaikan jumlah } \\
\mathbf{C O}_{\mathbf{2}} \text { terserap (\%) }\end{array}$ \\
\hline $5-10$ & 7,12 & 6,92 \\
\hline $10-15$ & 3,09 & 2,54 \\
\hline $15-20$ & 1,50 & 2,08 \\
\hline $20-25$ & 1,31 & 1,48 \\
\hline $25-30$ & 0,90 & 1,03 \\
\hline $30-35$ & 0,83 & 0,91 \\
\hline $35-40$ & 0,65 & 0,60 \\
\hline $40-45$ & 0,39 & 0,32 \\
\hline $45-50$ & 0,06 & 0,04 \\
\hline Total & 15,80 & 15,90 \\
\hline
\end{tabular}

Mekanisme penyerapan pengotor dengan 2 kolom adsorpsi dilakukan secara bergantian. Satu kolom selalu beroperasi, dan satu kolom yang lain pada kondisi standby (siap siaga). Pada saat sebuah kolom/bed beroperasi (in operation) maka aliran bertekanan dikompressikan ke kolom tersebut untuk dibersihkan. Gas yang keluar dari kolom Molecular Sieve kemurniannya selalu dipantau menggunakan Gas Chromatography secara terus menerus (online), dengan demikian apabila kolom Molecular Sieve telah mengalami kejenuhan maka keadaan tersebut segera diketahui.

Apabila Molecular Sieve telah mengalami kejenuhan, maka kolom tersebut harus di regenerasi. Proses regenerasi dilakukan dengan menutup aliran ke kolom yang sudah jenuh dan mengalihkan aliran tersebut ke kolom yang standby. Untuk selanjutnya kolom yang sudah jenuh, dibuka katupnya agar tekanannya turun menuju ke tekanan atmosfer, sehingga gas-gas pengotor yang tertangkap terlepas kembali.

\section{Simpulan}

Pemodelan adsorpsi dengan Molecular Sieve telah dilakukan dengan software ChemCAD. Hasil simulasi menunjukkan bahwa dengan adanya kenaikan tekanan dari 5 sampai 50 bar, mengindikasikan adanya kenaikan daya serap Molecular Sieve terhadap pengotor $\mathrm{CO}_{2}$ sebesar $15,90 \%$, sedangkan terhadap pengotor $\mathrm{H}_{2} \mathrm{O}$ sebesar $15,80 \%$. Berdasarkan hasil ini, pada desain SPH RDE10 akan 
ditentukan tekanan masuk ke kolom Molecular Sieve adalah 50 bar. Tekanan ini didapatkan dengan mengompressikan aliran masuk ke kolom dengan Kompressor untuk mendapatkan daya adsorpsi tinggi terhadap proses penyerapan pengotor $\mathrm{CO}_{2}$ dan $\mathrm{H}_{2} \mathrm{O}$.

\section{Kepustakaan}

[1] Subekti M., Bakhri S., Sunaryo G.R. The Simulator Development for RDE Reactor. J. Phys. Conf. Ser. 2018. 962(1)

[2] NATESAN K., A., PUROHIT, S.W. TAN, "Material Behavior in HTGR Environments", Argonne National Laboratory, NUREG/CR6824 ANL-0237, 2013

[3] Priambodo D., Pancoko, Sriyono M., Setiadipura T. Design of Helium Purification System for Indonesia Experimental Power Reactor- Reaktor Daya Eksperimental. Int. J. Mech. Eng. Technol. 2018. 6(7):1-7.

[4] Sriyono, Kusmastuti R., Bakhri S., Sunaryo G.R. Analysis of helium purification system capability during water ingress accident in $R D E$. J. Phys. Conf. Ser. 2018. 962(1):1-9

[5] Dibyo S., Sunaryo G.R., Bakhri S., Irianto I.D. Analysis on Operating Parameter Design to Steam Methane Reforming in Heat Application RDE. J. Phys. Conf. Ser. 2018. 962:012052.
[6] PERRY H., et.al., "Perry's Chemical Engineers' Handbook" $8^{\text {th }}$ Edition, Mc. Graw Hill, 2008

[7] BENNET J.E., et.al, "Pressure Swing Adsorption (PSA) Regenerative Chemical Filtration and Environmental Control System For The Colpro of Armoured Fighting Vehicles", Journal Air Control Technologies, Hawthorne Road, Staines, Middlesex, TWI8-3AY, ENGLAND, 2013

[8] DANGI P. GANGA et.al., "Adsorption Selectivity of $\mathrm{CO}_{2}$ Over $\mathrm{N}_{2}$ by Cation Exchange Zeolite L : Experimental and Simulation Studies", Journal of Material, CSIR, Bhavnagar, India, 2012

[9] MYERS A.L., "Adsorption in Porous Materials at High Pressure : Theory and Experiment", Journal of Chem. Engineers, Dept. of Chemical and Biomolecular Engineering, University of Pensnsylvania, Amerika Serikat, 2017

[10] ENDANG WIDJAJANTI LAKSONO, "Analisis Daya Adsorpsi Suatu Adsorben", Jurnal Kimia, Jurusan Kimia, FMIPA, Universitas Negeri Yogyakarta, 2012

[11] GASTALDI,O., et al., "Helium Purification", Proceedings HTR 2006, $3^{\text {rd }}$ International Topical Meeting on High Temperature Reactor Technology, Johannesburg, South Africa, 2006.

[12] PT. INGENIOUS,"CHEMCAD Process Simulation", Manual Book of Software Training, BATAN, Serpong, 2012

[13] CROFT T DAVID, et.al.,"Adsorbents for Pressure Swing Adsorption Regeneration", Journal of Energy, US Army Soldier and Biological Command, USA, 2016

[14] Sriyono, Topan Setiadupura, Geni R. Sunaryo, "Carbon Dust in Primary Coolant of RDE: Its Problem and Solution", Jurnal Tri Dasa Mega, Vol. 20, No.2, Juni 2018, pp. 89-98 